Original Paper

\title{
Contribution of Nrf2 to Atherogenic Phenotype Switching of Coronary Arterial Smooth Muscle Cells Lacking CD38 Gene
}

\author{
Ming Xua,b Xiao-Xue Li ${ }^{a}$ Lei Wang ${ }^{a}$ Mi Wang ${ }^{a}$ Yang Zhang ${ }^{a, c}$ Pin-Lan Lia \\ aDepartment of Pharmacology and Toxicology, School of Medicine, Virginia Commonwealth University, \\ Richmond, Virginia, USA; ${ }^{b}$ Department of Clinical Pharmacy, School of Basic Medical and Clinical \\ Pharmacy, China Pharmaceutical University, Nanjing, China; 'Department of Pharmacological \& \\ Pharmaceutical Sciences, College of Pharmacy, University of Houston, Houston, Texas, USA
}

\section{Key Words}

CD38 • Dedifferentiation • Atherogenesis • Nrf2 • Vascular smooth muscle

\begin{abstract}
Background/Aims: Recent studies have indicated that CD38 gene deficiency results in dedifferentiation or transdifferentiation of arterial smooth muscle cells upon atherogenic stimulations. However, the molecular mechanisms mediating this vascular smooth muscle (SMC) phenotypic switching remain unknown. Methods \& Results: In the present study, we first characterized the phenotypic change in the primary cultures of coronary arterial myocytes (CAMs) from $\mathrm{CD}^{-1-}$ mice. It was shown that CD38 deficiency decreased the expression of contractile marker calponin, SM22 $\alpha$ and $\alpha$-SMA but increased the expression of SMC dedifferentiation marker, vimentin, which was accompanied by enhanced cell proliferation. This phenotypic change in $\mathrm{CD} 38^{-1-}$ CAMs was enhanced by 7-ketocholesterol (7-Ket), an atherogenic stimulus. We further found that the CD38 deficiency decreased the expression and activity of nuclear factor E2-related factor 2 (Nrf2), a basic leucine zipper (bZIP) transcription factor sensitive to redox regulation. Similar to CD38 deletion, Nrf2 gene silencing increased CAM dedifferentiation upon 7-Ket stimulation. In contrast, the overexpression of Nrf2 gene abolished 7-Ket-induced dedifferentiation in CD38-- CAMs. Given the sensitivity of Nrf2 to oxidative stress, we determined the role of redox signaling in the regulation of $\mathrm{Nrf} 2$ expression and activity associated with CD38 effect in CAM phenotype changes. It was demonstrated that in CD38\% CAMs, 7-Ket failed to stimulate the production of $\mathrm{O}_{2}^{-}$, while in CD38 $8^{+/+}$CAMs 7-Ket induced marked $\mathrm{O}_{2}^{-}$production and enhancement of Nrf2 activity, which was substantially attenuated by NOX4 gene silencing. Finally, we demonstrated that 7-Ket-induced and NOX4dependent $\mathrm{O}_{2}^{-}$production was inhibited by $8-\mathrm{Br}-\mathrm{CADPR}$, an antagonist of CADPR or NED-19, an antagonist of NAADP as product of CD38 ADP-ribosylcyclase, which significantly inhibited the level of cytosolic $\mathrm{Ca}^{2+}$ and the activation of Nrf2 under 7-Ket. Conclusion: Taken together, these results suggest that CD38 activity is required for 7-Ket-induced $\mathrm{Ca}^{2+}$ and consequently $\mathrm{O}_{2}$ production in CAMs, which increases Nrf2 activity to maintain their differentiated status. M. Xu and X.-X. Li contributed equally to this work.

Pin-Lan Li, MD, PhD

Department of Pharmacology and Toxicology, Virginia Commonwealth University, School of Medicine, 1220 East Broad Street, P.O. Box 980613, Richmond, VA 23298, (USA) Tel. 804 828-4793, Fax 804 828-2117, E-Mail pli@vcu.edu
\end{abstract}

KARGER 125 


\section{Cellular Physiology Cell Physiol Biochem 2015;37:432-444 \begin{tabular}{c|l|} 
DOI: 10.1159/000430366 & O 2015 S. Karger AG, Basel \\
\hline and Biochemistry
\end{tabular} \\ Xu et al.: Nrf2 in Atherogenic Phenotype Switching of Arterial Myocytes}

When CD38 gene expression and function are deficient, the Nrf2 activity is suppressed, thereby leading to phenotypic switching of CAMs.

Copyright $(2015$ S. Karger AG, Basel

\section{Introduction}

Although vascular smooth muscle cells (VSMCs) undergo remarkable phenotypic switching during development and progression of vascular diseases such as atherosclerosis [1], the mechanism mediating this phenotypic changes of VASMCs remain poorly understood. Recent studies have indicated that CD38 is a multifunctional enzyme responsible for the production and metabolism of cyclic ADP-ribose (CADPR) and nicotinic acid adenine dinucleotide phosphate (NAADP) in a variety of mammalian cells including VSMCs, which play important roles in the regulation of vascular function [2-4]. In particular, this CD38mediated signaling pathway has been implicated in the regulation of cell differentiation of stem cell or tumor cell behaviors [5-6]. More recently, we demonstrated that the CD38 deficiency decreased contractile phenotype in CAMs and increased collagen deposition in coronary arterial wall from mice exposed to the high-fat Western diet [2]. It has been suggested that CD38 signaling pathway may play a critical role in the maintenance of the contractile phenotype in CAMs. However, it remains unknown how CD38 signaling pathway works to mediate this phenotypic change in CAMs.

Nuclear factor erythroid 2-related factor 2 (Nrf2), a basic leucine zipper transcription factor, plays a critical role in protecting cells from oxidative stress [7]. Some recent studies have reported that Nrf2 could be a new therapeutic target to prevent atherosclerosis [811]. Given previous reports that CD38 importantly controls NOX4-mediated intracellular $\mathrm{O}_{2}{ }^{-}$ production in CAMs [12], it is likely that a redox-sensitive Nrf2 activity may be suppressed by deficient expression and function of CD38 and that Nrf2 may serve as a signaling mechanism to participate in phenotypic switching of CAMs when CD38 gene is lost or deficiently expressed.

To test this hypothesis, the present study used the primary cultures of CAMs to confirm that genetic deficiency of CD38 results in the switching of differentiated phenotype into atherogenic status in CAMs as shown by upregulation of dedifferentiated markers, enhanced proliferation, and production of extracellular matrix (ECM) proteins. This phenotypic switching was enhanced by 7-ketocholesterol (7-Ket), a prototype atherogenic stimulus abundant in oxidized low density lipoprotein (ox-LDL). Then, we went on to reveal that nucleus Nrf2 protein expression and activity are inhibited by the genetic deficiency of CD38 and that this inhibition of Nrf2 expression and activity contributes to the effect of CD38 deficiency in phenotype switching of CAMs. Lastly, we demonstrated that the mechanisms underlying Nrf2 inhibition in CAMs lacking CD38 gene are dependent upon NOX4-associated redox regulation.

\section{Materials and Methods}

\section{Mice}

Mice were purchased from the Jackson Laboratory. Eight-week old male and female mice were used in all experiments. All experimental protocols were reviewed and approved by the Institutional Animal Care and Use Committee of the Virginia Commonwealth University.

Isolation and culture of mouse CAMs

CAMs were isolated from mice as previously described [13]. In brief, mice were deeply anesthetized with an intraperitoneal injection of pentobarbital sodium $(25 \mathrm{mg} / \mathrm{kg})$. The heart was excised with an intact aortic arch and immersed in a petri dish filled with ice-cold Krebs-Henseleit $(K H)$ solution (in mM: 20 HEPES, $128 \mathrm{NaCl}, 2.5 \mathrm{KCl}, 2.7 \mathrm{CaCl}_{2}, 1 \mathrm{MgCl}_{2}, 16$ glucose, $\mathrm{pH}$ 7.4). A 25-gauge needle filled with Hank's buffered saline solution (HBSS) (in mM: $5.0 \mathrm{KCl}, 0.3 \mathrm{KH}_{2} \mathrm{PO}_{4}, 138 \mathrm{NaCl}, 4.0 \mathrm{NaHCO}_{3}, 0.3 \mathrm{Na}_{2} \mathrm{HPO}_{4} \cdot 7 \mathrm{H}_{2} \mathrm{O}$, 5.6 D-glucose, and 10 HEPES, with $2 \%$ antibiotics mixtue) was inserted into the aortic lumen, while the whole heart remained in the ice-cold HBSS. The tip of the needle was inserted deep into the heart that 


\section{Cellular Physiology Cell Physiol Biochem 2015;37:432-444 \begin{tabular}{ll|l} 
and Biochemistry & $\begin{array}{l}\text { DOI 10.1159/000430366 } \\
\text { Published online: August 28, } 2015\end{array}$ & $\begin{array}{l}\text { O 2015 S. Karger AG, Basel } \\
\text { www.karger.com/cpb }\end{array}$ \\
\cline { 2 - 3 }
\end{tabular} \\ Xu et al.: Nrf2 in Atherogenic Phenotype Switching of Arterial Myocytes}

is approximate to the aortic valve. Then, the needle was tied in place with the needle tip as close to the base of the heart as possible. The infusion pump was started with a 20-ml syringe containing warm HBSS through an intravenous extension set at a rate of $0.1 \mathrm{ml} / \mathrm{min}$ for $15 \mathrm{~min}$. HBSS was replaced with a warm enzyme solution $(1 \mathrm{mg} / \mathrm{ml}$ collagenase type I, $0.5 \mathrm{mg} / \mathrm{ml}$ soybean trypsin inhibitor, $3 \%$ BSA, and $2 \%$ antibiotic-antimycotic mixture), which was flushed through the heart at a rate of $0.1 \mathrm{ml} / \mathrm{min}$. Perfusion fluid was collected at 30-, 60-, and 90-min of perfusion. At $90 \mathrm{~min}$, the heart was cut with scissors and the apex was opened to flush out the cells that collected inside the ventricle. The fluid was centrifuged at $1,000 \mathrm{rpm}$ for $10 \mathrm{~min}$, the cell-rich pellets were mixed with the one of the media described below, and the cells were plated on $2 \%$ gelatin-coated six-well plates and incubated in $5 \% \mathrm{CO}_{2}-95 \% \mathrm{O}_{2}$ at $37^{\circ} \mathrm{C}$. DMEM supplemented with $10 \%$ FBS, $10 \%$ mouse serum, and $2 \%$ antibiotics was used to culture isolated smooth muscle cells. The medium was replaced three days after cell isolation and then once or twice each week until the cells grew to confluence. As previously described [12], mouse CAMs were identified according to their morphology, immunohistological staining or Western blot analysis of marker proteins, and flow cytometric characteristics.

\section{Western blot analysis}

Western blot analysis was performed as we described previously [14]. In brief, proteins from the CAMs were extracted using sucrose buffer (20 mM HEPES, 1mM EDTA, 255 mM sucrose, cocktail o protease inhibitors (Roche), pH 7.4]. Nuclear protein was extracted from CAMs using a Cayman's Nuclear Extraction Kit (Cayman 10009277) according to the manufacturer's instruction. After boiling for 5 minutes at $95^{\circ} \mathrm{C}$ in a $5 \times$ loading buffer, $30 \mu \mathrm{g}$ of total proteins were separated by a $12 \%$ sodium dodecyl sulfate-polyacrylamide gel electrophoresis (SDS-PAGE). The proteins of these samples were then electrophoretically transferred at $100 \mathrm{~V}$ for 1 hour onto a PVDF membrane (Bio-Rad, USA). The membrane was blocked with 5\% nonfat milk in Tris-buffered saline with Tween 20. After washing, the membrane was probed with 1:1000 dilution of primary mouse or rabbit antibodies against vimentin (Santa Cruz), calponin (Santa Cruz), proliferating cell nuclear antigen (PCNA, Cell Signaling), smooth muscle 22 alpha (SM22 $\alpha$, Abcam), $\alpha$-smooth muscle ctin $(\alpha$-SMA, Abcam), Nrf2 (Santa Cruz), NOX1 (Abcam), NOX4 (Santa Cruz), $\beta$-actin (Santa Cruz), or LamB1(Abcam) overnight at $4^{\circ} \mathrm{C}$ followed by incubation with horseradish peroxidase-labeled IgG (1:5000) against primary antibodies. The immuno-reactive bands were detected by chemiluminescence methods and visualized on Kodak Omat X-ray films. Densitometric analysis of the images obtained from X-ray films was performed using the Image J software (NIH).

\section{Proliferation assay}

The proliferation of CAMs was quantified using an Aqueous One Solution Cell Proliferation Assay kit (Promega) according to the manufacturer's instruction as we previously described [15]. Cells were cultured in a 96-well plate (2,000 cells per well) with or without treatment as indicated. After 48 hours, cells were incubated with $20 \mu \mathrm{L}$ Aqueous One Solution for $60 \mathrm{~min}$ at $37^{\circ} \mathrm{C}$. Then, the absorbance (at $490 \mathrm{~nm}$ ) of each sample was measured using a microplate reader. Calibration curves showed the fluorescence reading to be proportional to the cell number. The proliferation rate was obtained by calculating the fold change in the cell number of each sample before and after 48-hour incubation.

\section{Measurement of Nrf2 activity}

Nrf2 activity was measured by an Nrf2 transcription factor assay kit (Cayman, 600590) according to the manufacturer's instruction. Cayman's Nrf2 transcription factor assay is a non-radioactive, colorimetric method for detecting specific transcription factor DNA binding activity in nuclear extracts. A specific double stranded DNA (dsDNA) sequence containing the Nrf2 response element is immobilized onto the wells of a 96-well plate. Nrf2 contained in nuclear extract samples will bind specifically to the Nrf2 response element. Nrf2 can be detected by addition of a specific Nrf2 antibody. A secondary antibody conjugated to HRP is added to provide a sensitive colorimetric readout at $450 \mathrm{~nm}$. Nrf2 activity was expressed as the fold change of the treatment group versus the control.

Immunofluorescent staining

CAMs on a 8-well chamber slide were fixed with 4\% paraformaldehyde (PFA) and then incubated with a blocking solution of $0.1 \%$ Triton X-100 in 5\% bovine serum albumin (BSA). This was followed by incubation 


\section{Cellular Physiology Cell Physiol Biochem 2015;37:432-444 \begin{tabular}{ll|l} 
DOI: 10.1159/000430366 & $\begin{array}{l}\text { O 2015 S. Karger AG, Basel } \\
\text { www.karger.com/cpb }\end{array}$ \\
\hline
\end{tabular} \\ Xu et al.: Nrf2 in Atherogenic Phenotype Switching of Arterial Myocytes}

with anti- $\alpha$-SMA (1:200, Abcam) or anti-Nrf2 (1:200, SantaCruz) primary antibody at $4^{\circ} \mathrm{C}$ overnight. After washing with phosphate-buffered saline containing $0.1 \%$ Tween-20 (PBST) three times, the slides were incubated with Alexa-555 secondary antibody (Life Technologies) for 1 hour at $37^{\circ}$, and then mounted in Vector shield mounting medium with DAPI (Vector Laboratories Inc.). Staining was visualized through sequential scanning on an Olympus laser scanning confocal microscope (Fluoview FV1000, Olympus, Japan) or fluorescentmicroscopy (BX41TF, Olympus, Japan).

\section{RNA interference}

Small interference RNAs (siRNAs) were commercially available (QIAGEN, CA), and the sequences were as follows: For NOX1 siRNA: 5'-UGG AGU CAC UCC AUU UGC AUC GAUA-3'; for NOX4 siRNA: 5'-UUU AGG GAC AGC CAA AUG AGC AGGC-3'. Nrf2 siRNA were purchased from Santa Cruz (sc-37049). siRNAs of NOX1, NOX4 and Nrf2 have been demonstrated to efficiently inhibit the protein expression of NOX1, NOX4 and Nrf2 as we recently described $[12,16]$. A scrambled small RNA (5'-AAU UCU CCG AAC GUG UCA CGU-3') was also confirmed no silecung of genes and used as a control in the present study. Transfection of siRNA was performed using the siLentFect Lipid Reagent (Bio-Rad, CA, USA) according to the manufacturer's instructions, and the efficiency of siRNA to silence different genes were confirmed with Western blot analysis.

Electron spin resonance (ESR) detection of $\mathrm{O}_{2}$

For detection of the $\mathrm{O}_{2}$ - production dependent on NADPH oxidase (NOX) in the membrane, CAMs were gently collected and resuspended in modified Krebs-Hepes buffer containing deferoximine $(100 \mu \mathrm{mol} / \mathrm{L}$; Sigma, St. Louis, MO, USA) and diethyldithiocarbamate ( $5 \mu \mathrm{mol} / \mathrm{L}$; Sigma). These mixtures containing $1 \times 10^{6}$ cells were subsequently mixed with $1 \mathrm{mM}$ of the $\mathrm{O}_{2} \cdots$-specific spin trap, 1-hydroxy-3- methoxycarbonyl2,2,5,5-tetramethylpyrrolidine ( $\mathrm{CMH}$ ) in the presence or absence of manganese-dependent superoxide dismutase (SOD) (200 U/ml; Sigma). The mixtures were then loaded into glass capillaries and immediately analyzed for $\mathrm{O}_{2}{ }^{-}$formation kinetics for $10 \mathrm{~min}$ in a Miniscope MS200 ESR spectrometer (Magnettech Ltd., Berlin, Germany) as described [12]. The ESR settings were as follows: biofield, 3350; field sweep, $60 \mathrm{G}$; microwave frequency, $9.78 \mathrm{GHz}$; microwave power, $20 \mathrm{~mW}$; modulation amplitude, $3 \mathrm{G}$; 4096 points of resolution; receiver gain, 50 for cells. The SOD-sensitive $\mathrm{O}_{2}{ }^{-}$was calculated as specific signal of NOX activity. The results were expressed as the fold change of the treatment group versus the control.

\section{Nucleofection of CD38 cDNA and Nrf2 cDNA}

Both CD38 cDNA (Catalog\# MG204265) and Nrf2 cDNA plasmids (Catalog\# MG226717) were purchased from OriGene Technologies. Transfection of plasmids was performed using a 4D Nucleofector X-Unit (Lonza, CA, USA) according to the manufacturer's instructions, which was described in our recent studies [2]. Briefly, CAMs were trypsinized and centrifuged at $90 \times \mathrm{g}$ for 10 minutes. The cell pellet was resuspended in $100 \mu \mathrm{L}$ P1 Nucleofection solutions (Lonza) for Nucleofection (with the program code CM137). The program was chosen based on the fact that Nucleofection efficiency was over $80 \%$ as analyzed by flow cytometry using control GFP plasmids. For each Nucleofection sample, $2 \mu \mathrm{g}$ plasmid DNA was added in $100 \mu \mathrm{L}$ P1 Nucleofection solution. After Nucleofection, the cells were cultured in the DMEM medium for 24 hours and then were ready for treatment. The efficiency of CD38 cDNA and Nrf2 cDNA transfection was assessed by Western blot analyses [17].

\section{Fluorescent microscopic measurement of $\left[\mathrm{Ca}^{2+}\right]_{i}$ in CAMs}

A fluorescence image analysis system was used to determine $\left[\mathrm{Ca}^{2+}\right]_{\mathrm{i}}$ in CAMs with fura- 2 acetoxymethyl ester (fura-2) as an indicator as previously described [14], Having been loaded with $10 \mu \mathrm{M}$ fura-2 at room temperature for $30 \mathrm{~min}$, the cells were washed three times with $\mathrm{Ca}^{2+}$-free Hank's buffer. The ratio of fura-2 emissions, when excited at the wavelengths of 340 and $380 \mathrm{~nm}$, was recorded with a digital camera (Nikon Diaphoto TMD Inverted Microscope). Metafluor imaging and analysis software were used to acquire, digitize, and store the images for off-line processing and statistical analysis (Universal Imaging). The fluorescence ratio of excitation at $340 \mathrm{~nm}$ to that at $380 \mathrm{~nm}(\mathrm{~F} 340 / \mathrm{F} 380)$ was determined after background subtraction, and $\left[\mathrm{Ca}^{2+}\right]_{i}$ was calculated by using following equation: $\left[\mathrm{Ca}^{2+}\right]_{\mathrm{i}}=K_{\mathrm{d}} \beta\left[\left(\mathrm{R}-\mathrm{R}_{\min }\right) /\left(\mathrm{R}_{\max }-\mathrm{R}\right)\right]$, where $K_{\mathrm{d}}$ for the fura-2- $\mathrm{Ca}^{2+}$ complex is $224 \mathrm{nM} ; \mathrm{R}$ is the fluorescence ratio $\left(\mathrm{F}_{340} / \mathrm{F}_{380}\right) ; \mathrm{R}_{\max }$ and $\mathrm{R}_{\min }$ are the maximal and minimal fluorescence ratios measured by addition of $10 \mu \mathrm{M}$ of $\mathrm{Ca}^{2+}$ ionophore ionomycin to $\mathrm{Ca}^{2+}$-replete solution $\left(2.5 \mathrm{mM} \mathrm{CaCl}_{2}\right)$ and $\mathrm{Ca}^{2+}$-free solution (5 mM EGTA), respectively; and $\beta$ is the fluorescence ratio at 380-nm excitation determined at $\mathrm{R}_{\min }$ and $\mathrm{R}_{\text {max }}$, respectively. 
Statistics

Data are presented as means \pm SE. Significant differences between and within multiple groups were examined using ANOVA for repeated measures, followed by Duncan's multiple-range test. The Student's $t$ test was used to detect significant differences between two groups. $P<0.05$ was considered statistically significant.

\section{Results}

\section{Phenotypic characterization in CD38\% CAMs}

A hallmark feature of VSMC phenotypic switching is featured by altered expression of VSMC selective contractile genes, including calponin, SM22 $\alpha$ and $\alpha$-SMA [18]. To examine whether CD38 regulates phenotypic switching in CAMs, CD38 gene knockout (CD38 ${ }^{-/}$) CAMs were used to compare with wild-type $\left(\mathrm{CD}^{+/+}\right)$CAMs. As showed in Fig. $1 \mathrm{~A}$ and $1 \mathrm{~B}$, the CD38 deficiency significantly decreased the protein level of calponin and SM22 $\alpha$, which was enhanced by 7-Ket in CAMs. Representative fluorescent images in Fig. 1E also showed that the fluorescent intensity of a contractile phenotype marker $\alpha$-SMA decreased in CD38\% CAMs compared with that in $\mathrm{CD}_{38^{+/+}} \mathrm{CAMs}$, particularly when they were treated with 7-Ket.

Conversely, the decrease of proteins associated with the contractile phenotype was generally accompanying by the increased dedifferentiation marker vimentin in CD38 ${ }^{-}$CAMs (Fig. 1C). The levels of PCNA, an excellent marker for cell proliferation, also increased in CD38\% CAMs under control and 7-Ket stimulation when compared with that from $\mathrm{CD}^{2} 8^{+/+}$ CAMs (Fig. 1D). As shown in Fig.1F, the proliferation rate of CAMs measured using an Aqueous

Fig. 1. Phenotypic characterization in CD38\% CAMs. CAMs from $\mathrm{CD}^{+/+}$and CD38\% mice were treated with atherogenic stimulus, 7-ketocholesterol (7-Ket, $10 \mu \mathrm{g} / \mathrm{ml}$ ) for 24 hours. Representative Western blot gel documents and summarized data showing the protein expression of calpo$\operatorname{nin}(\mathrm{A}), \mathrm{SM} 22 \alpha$ (B), vimentin (C), and PCNA (D). (E) Typical representative fluorescent images for $\alpha$-SMA staining. (F) Summarized data showing the proliferation rate of CAMs in $\mathrm{CD}_{38}^{+/+}$ and $\mathrm{CD} 38^{-/}$CAMs. ${ }^{*} P<0.05, \quad \mathrm{CD} 38^{+/+}$ treated vs. $\mathrm{CD} 38^{+/+}$ control; \# $P<0.05$, $\mathrm{CD}^{2} 8^{+/+}$vs. $\mathrm{CD} 38^{-/-}$ CAMs $(n=6)$.

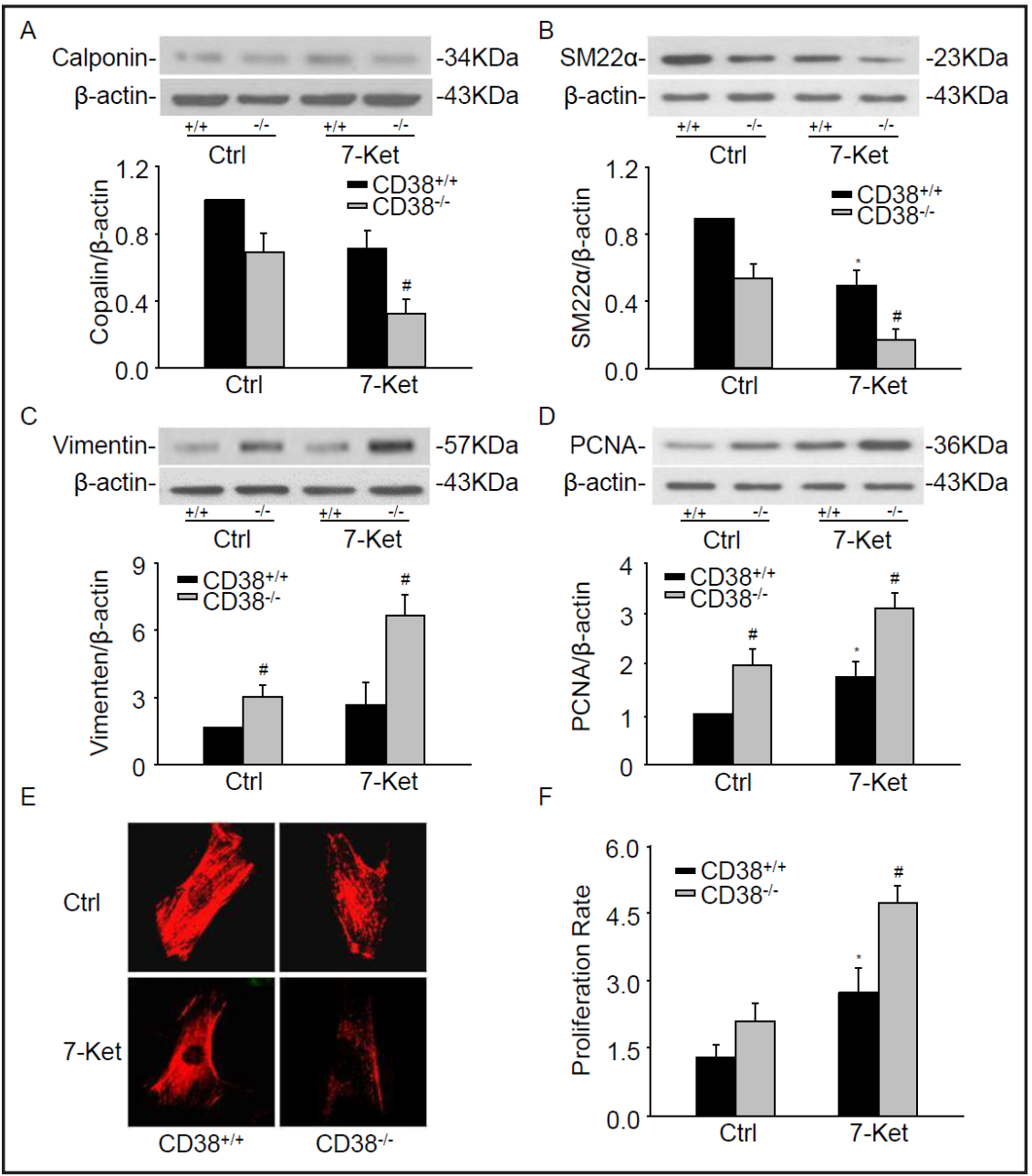


Fig. 2. CD38 deficiency inhibited the activation of Nrf2. Representative Western blot gel docuzed data showing the protein expression of nuclear Nrf2 in CD38/. and $\mathrm{CD}^{2} 8^{+/+} \mathrm{CAMs}$ (A) or $\mathrm{CD} 38^{\%} \mathrm{CAMs}$ transfected CD38 cDNA plasmids (B). (C) Typical representative fluorescent images for nuclear translocation of Nrf2. DAPI were used as a nuclear staining marker. (D) Summarized data showing nuclear Nrf2 activity of CAMs. ${ }^{*} P<0.05, \mathrm{CD}_{38}{ }^{+/+}$treated vs. $\mathrm{CD} 38^{+/+}$control; \# $P<0.05, \mathrm{CD} 38^{+/+}$vs. CD38\% CAMs $(\mathrm{n}=6)$. ments and summari-

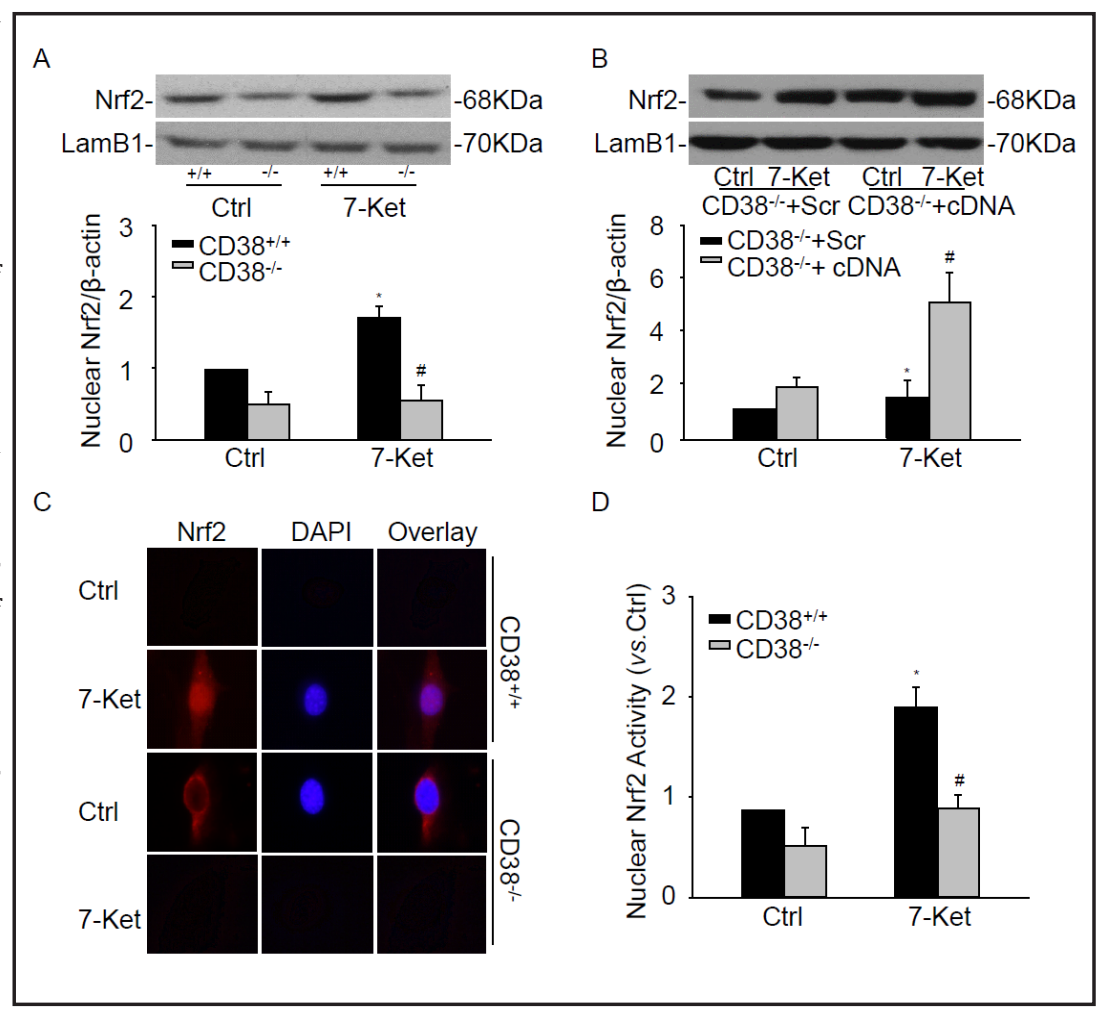

Fig. 3. Efficiency of $\mathrm{Nrf2}$ siRNA and cDNA transfection. Representative Western blot gel documents and summarized data showing the protein expression of $\mathrm{Nrf} 2$ after the transfection with Nrf2 siRNA (A) and cDNA(B). $\quad{ }^{*} P<0.05$, vs. Scramble control $(n=6)$.

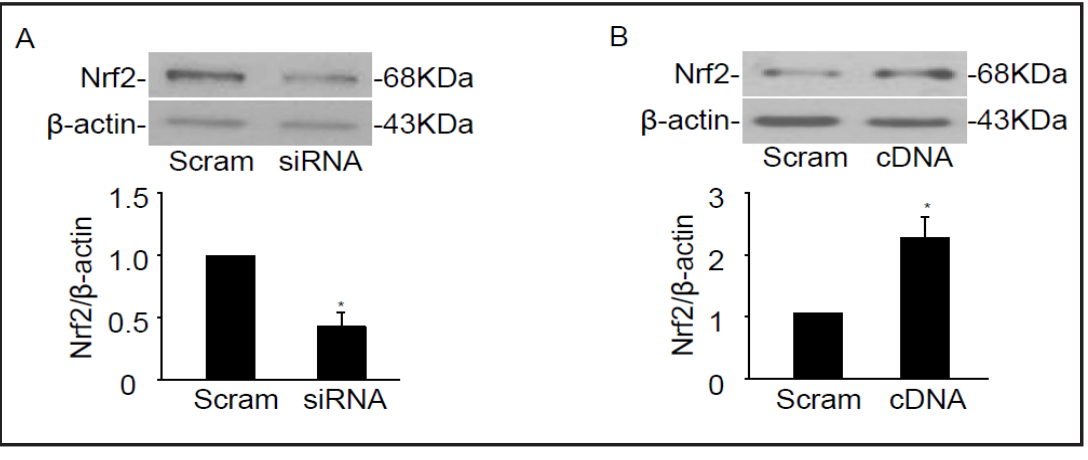

One Solution Cell Proliferation Assay kit markedly increased in CD38\%- CAMs compared to $\mathrm{CD}^{+/+}$cells, which enhanced by 7-Ket (Fig. 1F).

\section{CD38 deficiency inhibited the activation of Nrf2}

To gain further insights into the molecular mechanisms underlying the phenotypic switching due to lack of CD38 in CAMs, the possible involvement of transcription factor, Nrf2 was examined as a downstream regulator. Since Nrf2 activation is dependent on its translocation in nuclei to activate expression of its target genes, we first attempted to examine the nuclear accumulation of Nrf2 protein. As showed in Fig. 2A, the nuclear Nrf2 protein level dramatically decreased in CD38/- CAMs compared with CD38 ${ }^{+/+}$CAMs under 7-Ket treatment. In contrast, CD38 overexpression by transfection of CD38 full length cDNA restored the protein level of nuclear Nrf2 in CD38\% CAMs (Fig. 2B).

The nuclear translocation of Nrf2 from cytosol under 7-Ket was confirmed by immunolocalization of anti-Nrf2 antibody using Fluorescent microscopy (Fig. 2C). The assay of Nrf2 activity was performed using Cayman's Nrf2 transcription factor assay kit. As shown in Fig. 2D, the nuclear Nrf2 activity was dramatically decreased in CD38\%-CAMs under 7-Ket stimulation. All these data strongly suggest that the activation of Nrf2 upon 7-Ket stimulation is dependent on the normal expression of CD38 gene. 
Fig. 4. Nrf2 deficiency changed the phenotypic marker in CAMs. CD38 ${ }^{+/+}$CAMs were transfected with Nrf2 siRNA under the treatment with 7-Ket for 24 hours. Representative Western blot gel documents and summarized data showing the protein expression of calponin (A), SM22 $\alpha$ $(B)$, vimentin $(C)$, and PCNA (D). (E) Typical representative fluorescent images for $\alpha$-SMA staining. (F) Summarized data showing the proliferation rate of CAMs in $\mathrm{CD}^{2} 8^{+/+}$and CD38\% CAMs. ${ }^{*} P<0.05$ vs. Scramble control; \# $P<0.05$ vs. Scramble 7 -Ket $(n=6)$.

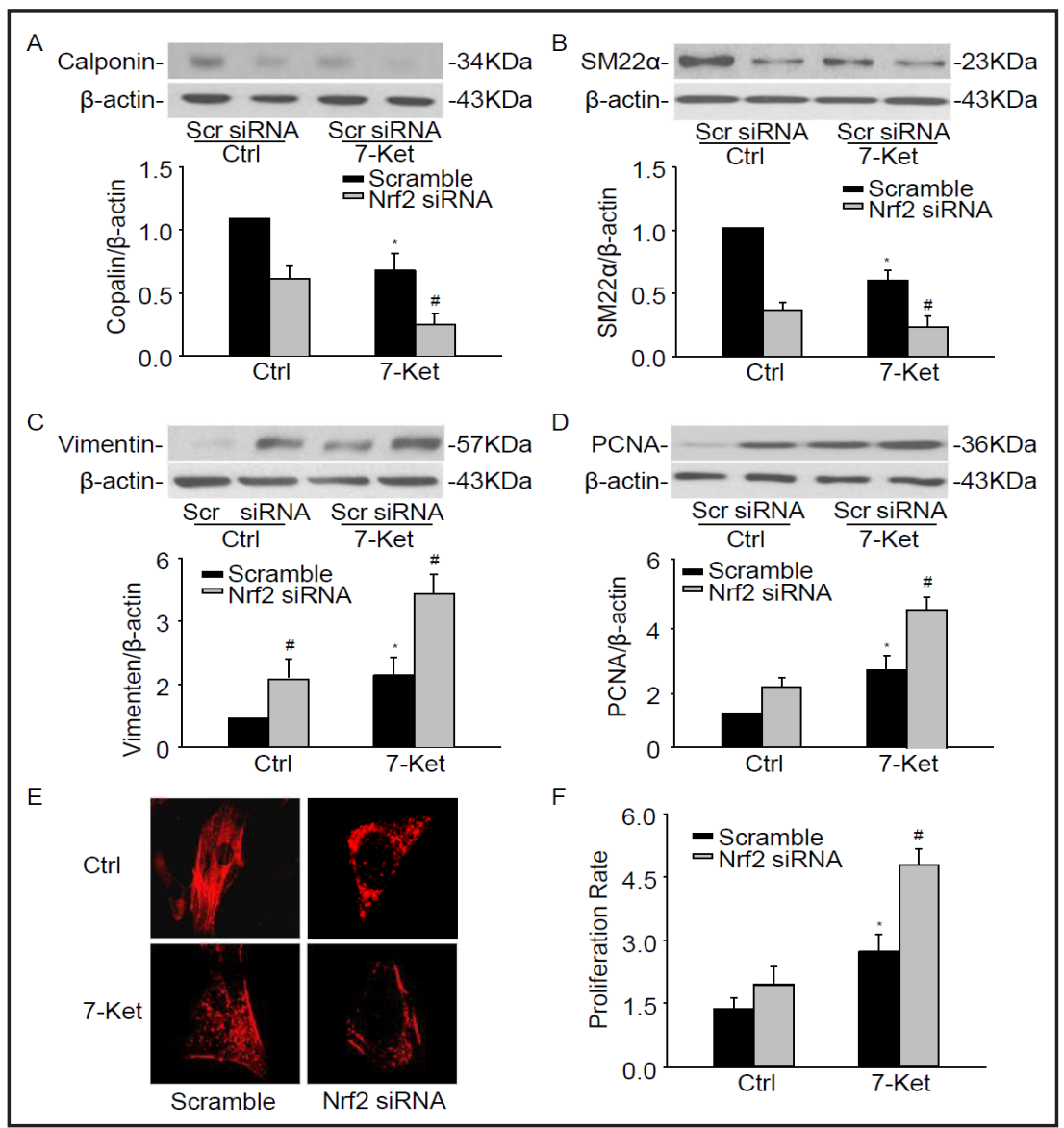

Nrf2 deficiency changed the phenotypic marker in CAMs

To elucidate the role of Nrf2 on phenotypic switching in CAMs, we next examined whether CAMs lacking Nrf2 exhibit a more proliferative status. Nrf2 siRNA was transfected into CAMs and the phenotypic markers described above were observed. We have demonstrated that Nrf2 siRNA inhibit the protein expression of Nrf2 by $57.4 \%$ (Fig. 3A). As showed in Fig. 4A and $4 \mathrm{~B}, \mathrm{Nrf2}$ deficiency resulted in a significant decrease in the protein level of calponin and SM22 $\alpha$ as well as in $\alpha$-SMA fluorescent staining under 7-Ket stimulation (Fig. 4E). Conversely, 7-Ket-induced vimentin expression and PCNA were further augmented in CAMs with silencing of Nrf2 gene (Fig. 4C and 4D), accompanied with an increase in proliferation rate of CAMs in response to 7-Ket stimulation (Fig. 4F).

To further confirm the Nrf2 on phenotypic change in CAMs, Nrf2 full length cDNA plasmids were transfected into CD38\% CAMs. We have demonstrated that Nrf2 cDNA increased the protein expression of Nrf2 by 2.42 -fold (Fig. 3B). As showed in Fig. 5A-F, Nrf2 overexpression restored the expression of phenotypic markers and cell proliferation observed in CD38\% CAMs. These results suggest that Nrf2 determines the proliferative phenotype in $\mathrm{CD} 38^{\%} \mathrm{CAMs}$.

\section{The effect of NOX4 gene silencing on Nrf2 translocation into the nucleus}

We demonstrated that CD38 importantly controls NAD(P)H oxidase-mediated intracellular $\mathrm{O}_{2}-$-production in CAMs[12]. Here, we found that NOX4 protein expression decreased in CD38 $\%$ CAMs compared with $\mathrm{CD}^{\circ 8^{+/}}$CAMs (Fig. 6A). However, there was no significant difference in NOX1 protein expression between CD38 $\%$ and CD38 ${ }^{+/+}$CAMs under control and 7-Ket treatment (Fig. 6B). By using the ESR spectrometry, we further determined that 7-Ket markedly induced $\mathrm{O}_{2}^{-}$production, which was almost blocked in CD38\% CAMs (Fig. 6C). We demonstrated that NOX1 and NOX4 siRNA inhibit the protein expression of NOX1 
Fig. 5. Nrf2 deficiency changed the phenotypic marker in CAMs. CD38\% CAMs were transfected with Nrf2 cDNA plasmids under the treatment with 7-Ket for 24 hours. Representative Western blot gel documents and summarized data showing the protein expression of calpo$\operatorname{nin}(\mathrm{A}), \mathrm{SM} 22 \alpha(\mathrm{B})$, Vimentin (C), and PCNA (D). (E) Typical representative fluorescent images for $\alpha$-SMA staining. (F) Summarized data showing the proliferation rate of CAMs in CD38 1- transfected with Nrf2 cDNA. ${ }^{*} P<0.05$, vs. Scramble control; \# $P<0.05$, vs. scramble 7 -Ket $(n=6)$.

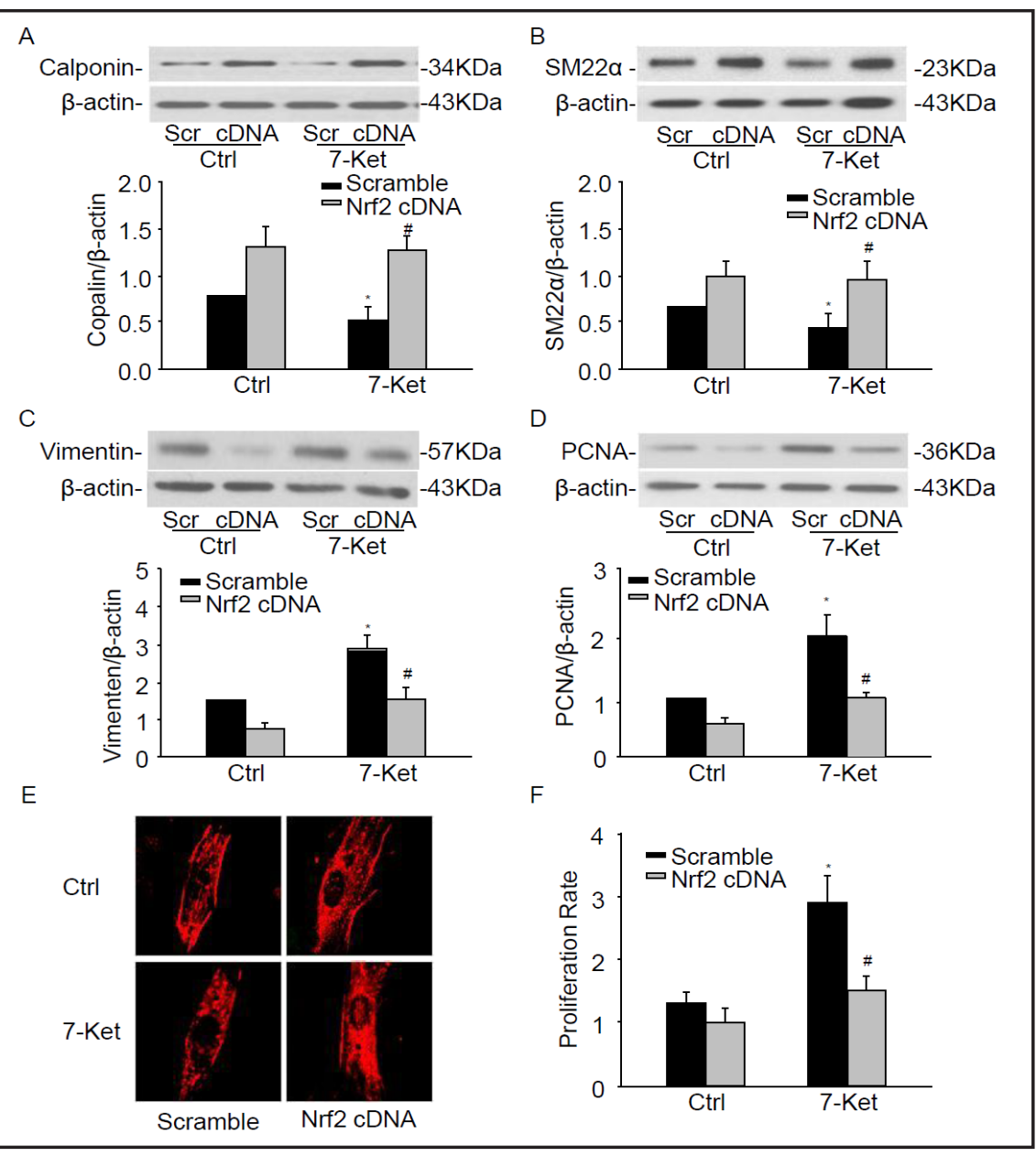

and NOX4 by $66.5 \%$ and $77.4 \%$, respectively [12]. Here we found that NOX4 siRNA, not NOX1 siRNA significantly inhibited $\mathrm{O}_{2}^{-}$production induced by 7-Ket (Fig. 6D).

In addition, using fluorescent microscopy we found that Nrf2 translocation decreased in CAMs transfected with NOX4 siRNA (Fig. 6E). Similarly, Nrf2 activity was also significantly inhibited in CAMs transfected with NOX4 siRNA (Fig. 6F). Taken together, these results clearly indicate that NOX4-dependent $\mathrm{O}_{2}^{-\cdot}$ production controls Nrf2 activation.

Contribution of CADPR or NAADP-sensitive $\mathrm{Ca}^{2+}$ signaling to $\mathrm{O}_{2}^{-}$production

CD38 functions as a multifunctional enzyme that produces cADPR and NAADP, potent intracellular $\mathrm{Ca}^{2+}$ mobilizers [4]. To demonstrate the effect of CD38-dependent $\mathrm{Ca}^{2+}$ signaling on the elevation of $\mathrm{O}_{2}{ }^{-}$and subsequently $\mathrm{Nrf} 2$ nuclear translocation, we incubated CAMs with cADPR antagonist, 8-Br-cADPR, or NAADP antagonist, NED-19 which significantly inhibited the level of cytosolic $\mathrm{Ca}^{2+}$ under 7-Ket (Fig. 7A and B). Importantly, Fig. 7C showed that 8-BrcADPR or NED-19 significantly inhibited 7-Ket-induced NOX-dependent $\mathrm{O}_{2}^{-}$production. We also observed nuclear translocation of Nrf2 and Nrf2 activity in 7-Ket-treated cells, which were inhibited in the presence of 8-Br-cADPR or NED-19 (Fig. 7D, E). These results demonstrate the role of cADPR or NED-19 -sensitive $\mathrm{Ca}^{2+}$ signaling in the control of $\mathrm{O}_{2}^{-}$ production, which contributes to the activation of Nrf2.

\section{Discussion}

In the present study, we provided novel evidences that a redox-sensitive transcription factor, Nrf2 plays an important role in 7-Ket stimulated phenotypic switching of CAMs (see working model in Fig. 8). This Nrf2-mediated action is critical for the occurrence of 
Fig. 6. NOX4-dependend $\mathrm{O}_{2}^{--}$is responsible for Nrf2 translocation into the nucleus. Representative Western blot gel documents and s u m m a ri z e d data showing the protein expression of NOX4 (A) and NOX1 (B) in $\mathrm{CD}_{38^{+/+}}$and CD38 $\%$ CAMs treated with 7-Ket. (C) Summarized ESR data showing the relative $\mathrm{O}_{2}-\quad$ production in $\mathrm{CD}_{38}^{+/+}$and CD38\% CAMs under control and treatment with 7-Ket. $\quad{ }^{*} P<0.05$, $\mathrm{CD}^{2} 8^{+/+}$treated vs. $\mathrm{CD}^{+/ /+}$control; \# $P<0.05$, $\mathrm{CD}^{+/+}$vs. CD38

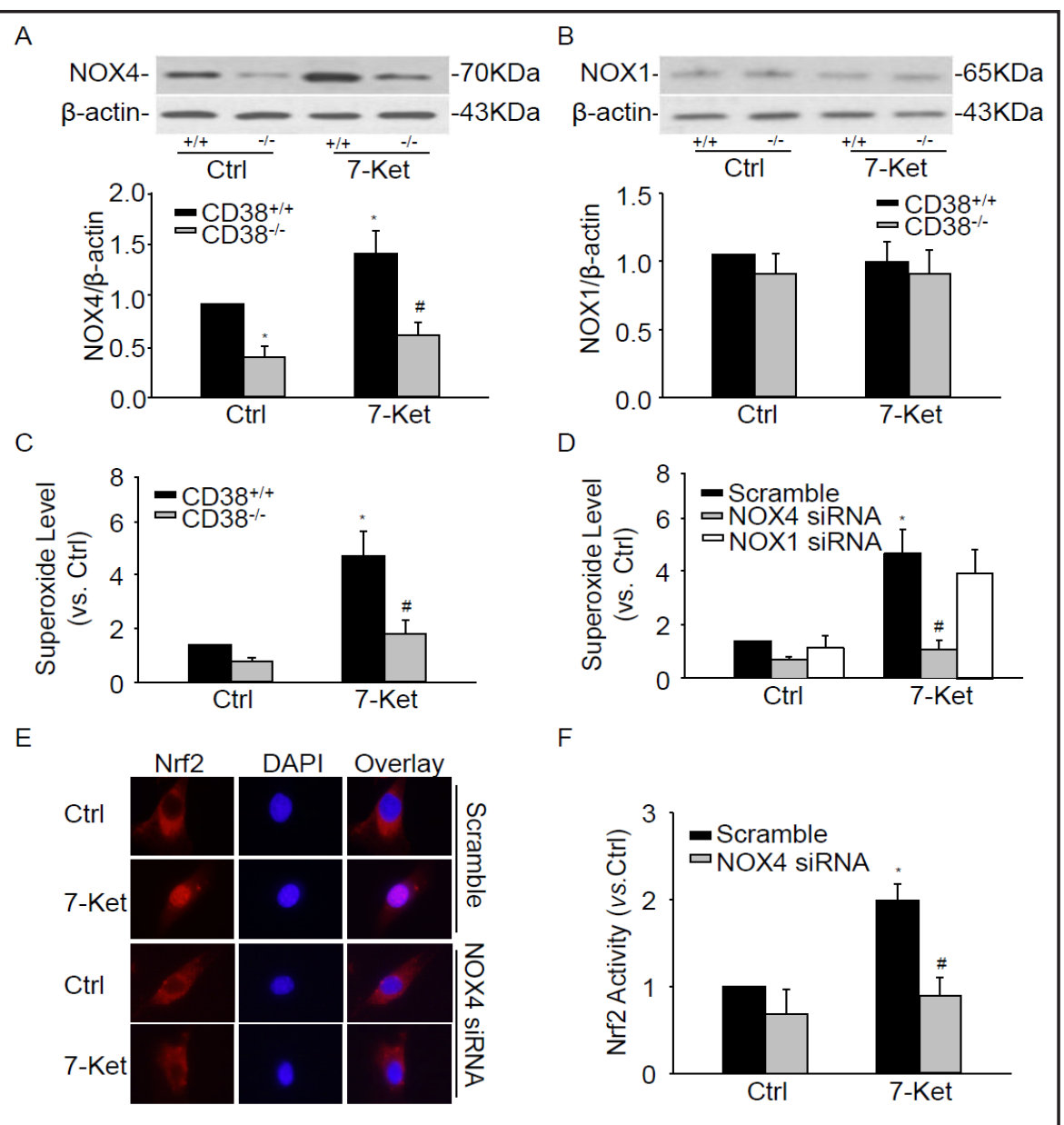

\% CAMs. (n=6). (D) Summarized ESR data showing the relative $\mathrm{O}_{2} \cdot$ production (SOD sensitive $\mathrm{O}_{2}{ }^{-}$) in $\mathrm{CD}^{-} 8^{+/+}$ CAMs transfected with NOX4 siRNA and NOX1 siRNA. (E) Typical representative fluorescent images for nuclear translocation of Nrf2 in CAMs transfected with NOX4 siRNA. (D) Summarized data showing nuclear Nrf2 activity of CAMs transfected with NOX4 siRNA. ${ }^{*} P<0.05$, vs. Scramble control; ${ }^{\#} P<0.05$, vs. Scramble 7-Ket $(n=6)$.

proliferative and atherosclerotic phenotype when CD38 gene was silenced or deleted. Furthermore, we confirmed that CD38-derived enzyme product CADPR and NAADP and associated $\mathrm{Ca}^{2+}$ signaling mechanisms are importantly implicated in the control of Nrf2 activation through NOX4-dependent $\mathrm{O}_{2}{ }^{--}$production.

The arterial SMCs within atherosclerotic lesions undergo phenotypic modulation and migration into the intima, where they proliferate, produce extracellular matrix, and participate in fibrous cap formation [19]. However, the mechanisms that control arterial SMC phenotypic switching remain poorly understood. In a previous study, we have demonstrated that CAMs from CD38\% mice had an enhanced dedifferentiated phenotype upon atherogenic stimulations compared to that from $\mathrm{CD}_{3} 8^{+/}$mice [2]. In the present study, we also demonstrated increased expression of dedifferentiation markers and decreased expression of contractile phenotype markers in CD38\% CAMs under atherogenic stimulations. These results in vivo and in vitro strongly indicate that CD38 is a critical enzyme for the control of CAMs phenotype during atherosclerotic lesions. It is imperative to explore the molecular mechanisms by which CD38-mediated signaling controls phenotype changes in CAMs.

It was shown that CD38 gene deletion decreased the expression of Nrf2 and reduced nuclear Nrf2 activity and translocation in CAMs upon atherogenic stimuli. This for the first time links CD38 and Nrf2 in CAMs, suggesting that Nrf2 is involved in pathological changes 
Fig. 7. cADPR or NAADP-sensitive $\mathrm{Ca}^{2+}$ regulates $\mathrm{O}_{2}^{-}$Production. CAMs were pretreated with 8-Br-cADPR $(30 \mu \mathrm{M})$ or NED-19 $(10 \mu \mathrm{M})$ and then stimulated with 7-Ket for 24 hours. Representative $\mathrm{Ca}^{2+}$ traces (A) and summarized data (B) showing the level of cytosolic $\mathrm{Ca}^{2+}$ in CAMs. (C) Summarized ESR data showing the relative $\mathrm{O}_{2}^{-}$production in CAMs before and after treatment with 8-Br-cADPR or NED-19. (D) Typical representative fluorescent images showing nuclear translocation of Nrf2 in CAMs pretreated with 8-Br-cADPR or NED-19. (E) Summarized data showing nuclear Nrf2 activity in CAMs pretreated with 8-Br-cADPR or NED-19. ${ }^{*} P<0.05$, vs. control; ${ }^{P} P<0.05$, vs. CAMs treated with 7-Ket $(\mathrm{n}=6)$.

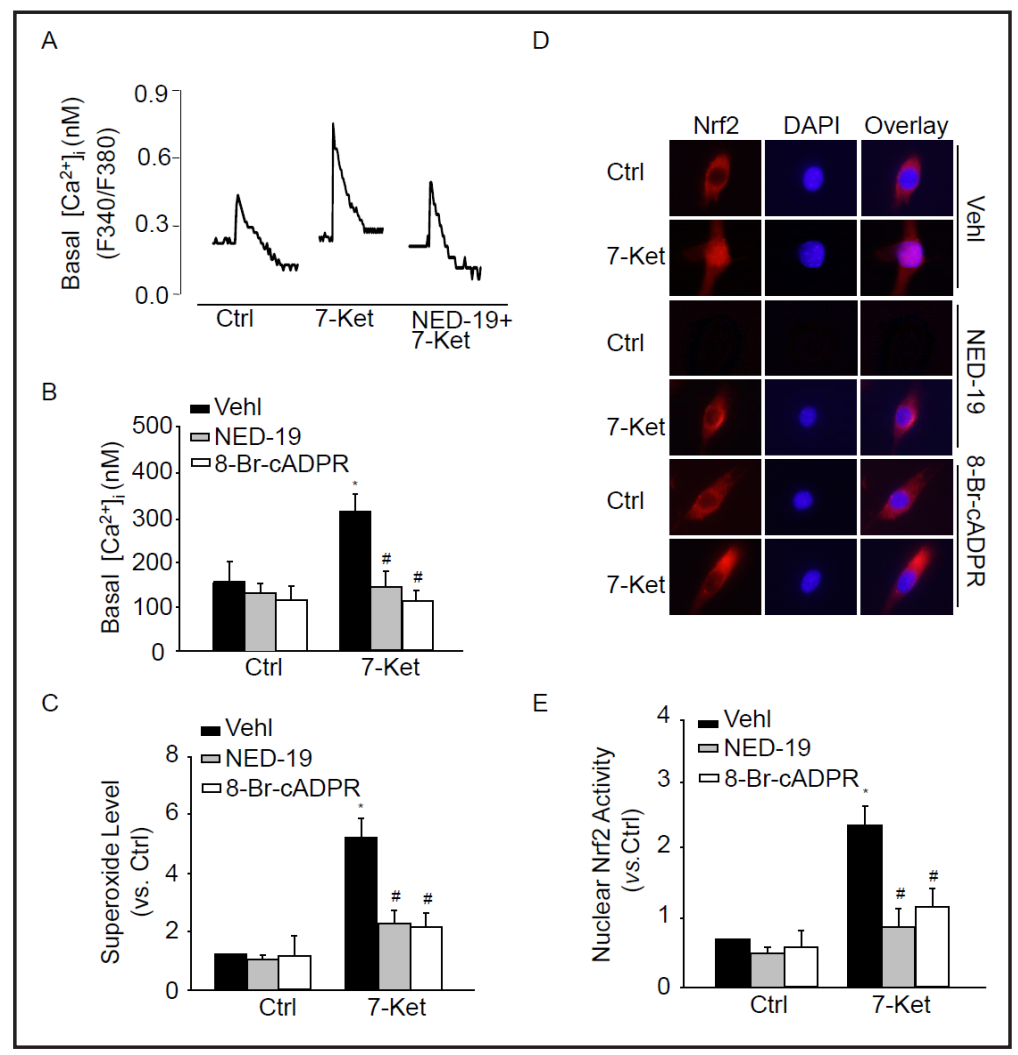

Fig. 8. Working model in this project. In this model, Nrf2 plays an important role in the occurrence of proliferative and atherosclerotic phenotype when CD38 gene was silenced or deleted. CD38-derived enzyme product cADPR and NAADP and associated $\mathrm{Ca}^{2+}$ signaling mechanisms are importantly implicated in the control of Nrf2 activation through NOX4-dependent $\mathrm{O}_{2}-$ production.

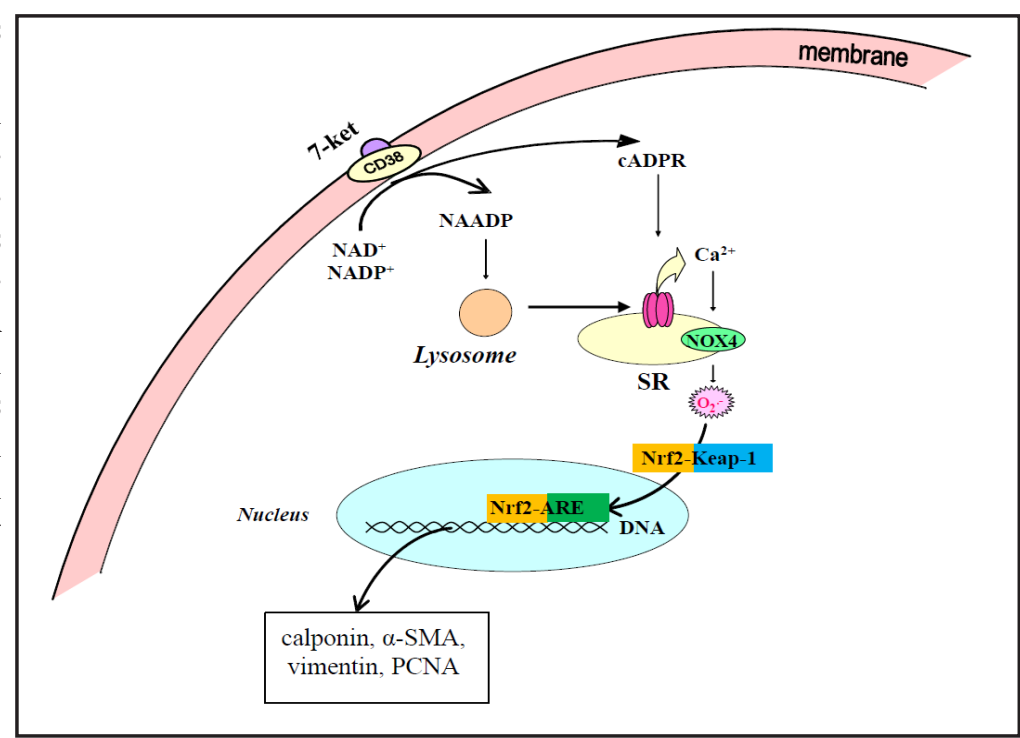

in different vascular cells during atherosclerosis. Recently, it has been reported that geraniol dietary or ellagic acid protects against atherosclerosis by Nrf2 activation in diet-induced experimental atherosclerosis $[8,20,21]$. In addition, shear force on arterial endothelial cells strongly activated Nrf2 and induced its nuclear translocation, thereby promoting athero-protective gene expression and related endothelial adaptation [11, 22]. However, there are some reports that disruption of Nrf2 exhibited significantly smaller plaque area in ApoE-mediated atherosclerosis in mice due to upregulation of CD36 [23]. It seems that the activation of Nrf2 during atherogenesis may play a dual role including anti- and proatherogenic role, which is associated with the experimental model and its action on different vascular beds. 


\section{Cellular Physiology Cell Physiol Biochem 2015;37:432-444 \begin{tabular}{l|l} 
and Biochemistry Published online: August 28, 2015 & $\begin{array}{l}\text { DO 2015 S. Karger AG, Basel } \\
\text { www.karger.com/cpb }\end{array}$ \\
\hline
\end{tabular} \\ Xu et al.: Nrf2 in Atherogenic Phenotype Switching of Arterial Myocytes}

In this regard, it was reported that Nrf2 regulates VSMCs migration and neointimal in vitro, and it alters the susceptibility of VSMCs to atherogenic stimuli [24]. However, a direct role of Nrf2 in phenotypic switching of these VSMCs has not been determined. In the present study, we determined the critical role of Nrf2 in phenotypic switching of CAMs by knocking down its gene, which mimicked the effects of CD38 deficiency on phenotypic switching in these CAMs. Moreover, we found that Nrf2 gene overexpression restored the phenotypic switching in CD38 $\%$ CAMs. These results support the view that Nrf2 functions as a key regulator for CD38-dependent phenotypic switching in CAMs upon the atherogenic stimulations. In previous studies, Nrf2 gene overexpression was also found to suppress human or rabbit aortic smooth muscle cell proliferation in vitro [25]. In other studies, the activation of Nrf2 has been shown to regulate the basal and inducible expression of cytoprotective, detoxifying and antioxidant genes[26] and that Nrf2-ARE-oxidoreductase-1 (NQ01) pathway may importantly contribute to the inhibition of the major molecules that lead to vascular damage and VSMCs proliferation and migration [10].

To further test how Nrf2 activity or translocation is altered by atherogenic stimuli in CD38 deficient CAMs, we examined the role of CD38 associated with redox signaling. NOX1, NOX2 and NOX4 were identified in vascular cells such as endothelial and smooth muscle cells[27]. However, in our previous studies and by others demonstrated that NOX2 had no significant action on extracellular and intracellular $\mathrm{O}_{2}^{-}$production in response to ANG II or oxotremorine $[12,28,29]$. In these studies, we have demonstrated that NOX1 primarily contribute to extracellular $\mathrm{O}_{2}{ }^{--}$production, but CD38 importantly controls NOX4-mediated intracellular $\mathrm{O}_{2}$-production in CAMs [12]. It is possible that $\mathrm{O}_{2}^{-}$-derived from $\mathrm{NOX} 4$ contributes to CD38-dependent Nrf2 activation in CAMs. Since our previous studies have also found that CD38-regulated intracellular $\mathrm{O}_{2}$ - production is primarily dependent on intracellular NOX4 activity [12], the present study addressed whether Nrf2-mediated phenotypic switching of CD38\% CAMs upon atherogenic stimuli is attributed to NOX4-dependent $\mathrm{O}_{2}{ }^{-"}$ production. It was found that 7-Ket failed to stimulate the production of $\mathrm{O}_{2}^{-}$in $\mathrm{CD}^{-/-} \mathrm{CAMs}$, but indeed induced marked $\mathrm{O}_{2}^{-}$production and enhancement of $\mathrm{Nrf2}$ activity in $\mathrm{CD}^{-1 /+} \mathrm{CAMs}$. This $\mathrm{O}_{2}^{-}$ production and consequent enhancement of $\mathrm{Nrf} 2$ activity in $\mathrm{CD} 38^{+/+} \mathrm{CAMs}$ were substantially attenuated by NOX4 gene silencing, but not by NOX1 knocking down. These results provide convincing evidence that NOX4 derived $\mathrm{O}_{2}{ }^{-*}$ regulates Nrf2 activity and thereby determines the phenotypic transition of CAMs into proliferative and sclerotic status. Although we did not attempt to test how $\mathrm{O}_{2}^{-}$regulates Nrf2 activity, previous studies have shown that Nrf2 translocation to the nucleus and its activity are related to the action $\mathrm{O}_{2}^{-}$to target the Nrf2Keap1 complex [30, 31]. Under resting conditions, Keap1 plays a critical role in the control of Nrf2 levels in the cells[32]. $\mathrm{O}_{2}^{-}$target the Nrf2-Keap1 complex, dissociating Nrf2 from Keap1[33]. Stabilized Nrf2 is then translocated into the nucleus, where it transactivates related target genes. In CAMs, this regulation of Nrf2 translocation or function is dependent upon NOX4-dependent $\mathrm{O}_{2}^{--}$production, but not NOX1-derived $\mathrm{O}_{2}^{-}$despite that NOX1 has been shown to be enriched in membrane fraction to mainly produce extracellular $\mathrm{O}_{2}^{-}$[28].

Finally, we further explored the mechanism mediating NOX4-dependent $\mathrm{O}_{2}{ }^{-}$production in CAMs upon atherogenic stimulations. Previous studies have shown that NOX4 activity is sensitive to intracellular $\mathrm{Ca}^{2+}$ levels associated with cADPR-induced $\mathrm{Ca}^{2+}$ release from ryanodine receptor, a $\mathrm{Ca}^{2+}$ channel on the SR membrane [34]. Therefore, it is possible that CD38-derived cADPR production induces $\mathrm{Ca}^{2+}$ mobilization from the $\mathrm{SR}$ and thereby results in local activation of NOX4 on the SR. The current study indeed demonstrated that cADPR from CD38-cyclic ADP-ribosylcyclase was involved in 7-Ket-induced $\mathrm{Ca}^{2+}$ release. Furthermore, cADPR-dependent $\mathrm{Ca}^{2+}$ release was shown to regulate Nrf2 activation. In addition, NAADP, another product from CD38-cyclic ADP-ribosylcyclase was also involved in 7-Ket-induced $\mathrm{Ca}^{2+}$ release to regulate Nrf2 activation. These findings provide direct evidence that cADPR or NAADP-induced intracellular $\mathrm{Ca}^{2+}$ mobilization contributes to the activation of Nrf2 in CAMs.

In conclusion, we demonstrated that upon atherogenic stimulation CD38 activity is required for 7-Ket-induced $\mathrm{O}_{2}{ }^{-}$production, which increases Nrf2 activity to maintain CAMs 


\section{Cellular Physiology Cell Physiol Biochem 2015;37:432-444 \begin{tabular}{l|l|l} 
DOI: 10.1159/000430366 & (C) 2015 S. Karger AG, Basel
\end{tabular} www.karger.com/cpb \\ Xu et al.: Nrf2 in Atherogenic Phenotype Switching of Arterial Myocytes}

in a differentiated status. When CD38 gene expression and function are deficient, the Nrf2 activity is suppressed via NOX4-dependent $\mathrm{O}_{2}^{-}$production leading to dedifferentiation of CAMs.

\section{Acknowledgments}

This study was supported by grants from the National Institutes of Health (HL 057244, HL075316, HL091464, and HL122937).

\section{Disclosure Statement}

None.

\section{References}

1 Gomez D, Owens GK: Smooth muscle cell phenotypic switching in atherosclerosis. Cardiovasc Res 2012;95:156-164.

2 Zhang Y, Xu M, Xia M, Li X, Boini KM, Wang M, Gulbins E, Ratz PH, Li PL: Defective autophagosome trafficking contributes to impaired autophagic flux in coronary arterial myocytes lacking cd38 gene. Cardiovasc Res 2014;102:68-78.

3 Xu M, Li XX, Ritter JK, Abais JM, Zhang Y, Li PL: Contribution of nadph oxidase to membrane cd38 internalization and activation in coronary arterial myocytes. PloS one 2013;8:e71212.

$4 \quad$ Li PL, Zhang Y, Abais JM, Ritter JK, Zhang F: Cyclic adp-ribose and naadp in vascular regulation and diseases. Messenger 2013;2:63-85.

5 Wei WJ, Sun HY, Ting KY, Zhang LH, Lee HC, Li GR, Yue J: Inhibition of cardiomyocytes differentiation of mouse embryonic stem cells by cd38/cadpr/ca2+ signaling pathway. J Biol Chem 2012;287:35599-35611.

6 Nipp RD, Volkheimer AD, Davis ED, Chen Y, Weinberg JB, Friedman DR: Cd38 variation as a prognostic factor in chronic lymphocytic leukemia. Leuk Lymphoma 2014;55:191-194.

7 DeNicola GM, Karreth FA, Humpton TJ, Gopinathan A, Wei C, Frese K, Mangal D, Yu KH, Yeo CJ, Calhoun ES, Scrimieri F, Winter JM, Hruban RH, Iacobuzio-Donahue C, Kern SE, Blair IA, Tuveson DA: Oncogene-induced nrf2 transcription promotes ros detoxification and tumorigenesis. Nature 2011;475:106-109.

8 Gupte AA, Lyon CJ, Hsueh WA: Nuclear factor (erythroid-derived 2)-like-2 factor (nrf2), a key regulator of the antioxidant response to protect against atherosclerosis and nonalcoholic steatohepatitis. Curr Diab Rep 2013;13:362-371.

9 Freigang S, Ampenberger F, Spohn G, Heer S, Shamshiev AT, Kisielow J, Hersberger M, Yamamoto M, Bachmann MF, Kopf M: Nrf2 is essential for cholesterol crystal-induced inflammasome activation and exacerbation of atherosclerosis. Eur J Immunol 2011;41:2040-2051.

10 Hur KY, Kim SH, Choi MA, Williams DR, Lee YH, Kang SW, Yadav UC, Srivastava SK, Jung M, Cho JW, Kim SG, Kang ES, Lee EJ, Lee HC: Protective effects of magnesium lithospermate $b$ against diabetic atherosclerosis via nrf2-are-nqo1 transcriptional pathway. Atherosclerosis 2010;211:69-76.

11 Dai G, Vaughn S, Zhang Y, Wang ET, Garcia-Cardena G, Gimbrone MA, Jr:: Biomechanical forces in atherosclerosis-resistant vascular regions regulate endothelial redox balance via phosphoinositol 3-kinase/akt-dependent activation of nrf2. Circ Res 2007;101:723-733.

12 Xu M, Zhang Y, Xia M, Li XX, Ritter JK, Zhang F, Li PL: Nad(p)h oxidase-dependent intracellular and extracellular o2*- production in coronary arterial myocytes from cd38 knockout mice. Free Radic Biol Med 2012;52:357-365.

13 Teng B, Ansari HR, Oldenburg PJ, Schnermann J, Mustafa SJ: Isolation and characterization of coronary endothelial and smooth muscle cells from a1 adenosine receptor-knockout mice. Am J Physiol Heart Circ Physiol 2006;290:H1713-1720. 


\section{Cellular Physiology Cell Physiol Biochem 2015;37:432-444 \begin{tabular}{l|l} 
DOI: 10.1159/000430366 & (C) 2015 S. Karger AG, Basel
\end{tabular} and Biochemistry Published online: August 28, 2015 \\ Xu et al.: Nrf2 in Atherogenic Phenotype Switching of Arterial Myocytes}

14 Xu M, Li XX, Chen Y, Pitzer AL, Zhang Y, Li PL: Enhancement of dynein-mediated autophagosome trafficking and autophagy maturation by ros in mouse coronary arterial myocytes. J Cell Mol Med 2014;18:2165-2175.

15 Devlin CM, Leventhal AR, Kuriakose G, Schuchman EH, Williams KJ, Tabas I: Acid sphingomyelinase promotes lipoprotein retention within early atheromata and accelerates lesion progression. Arterioscler Thromb Vasc Biol 2008;28:1723-1730.

16 Wang M, Abais JM, Meng N, Zhang Y, Ritter JK, Li PL, Tang WX: Upregulation of cannabinoid receptor-1 and fibrotic activation of mouse hepatic stellate cells during schistosoma j. Infection: Role of nadph oxidase. Free Radic Biol Med 2014;71:109-120.

17 Zhang F, Xia M, Li PL: Lysosome-dependent ca(2+) release response to fas activation in coronary arterial myocytes through naadp: Evidence from cd38 gene knockouts. Am J Physiol Cell Physiol 2010;298:C12091216.

18 Wanjare M, Kusuma S, Gerecht S: Perivascular cells in blood vessel regeneration. Biotechnol J 2013;8:434447.

19 Doran AC, Meller N, McNamara CA: Role of smooth muscle cells in the initiation and early progression of atherosclerosis. Arterioscler Thromb Vasc Biol 2008;28:812-819.

20 Ding Y, Zhang B, Zhou K, Chen M, Wang M, Jia Y, Song Y, Li Y, Wen A: Dietary ellagic acid improves oxidantinduced endothelial dysfunction and atherosclerosis: Role of nrf2 activation. Int J Cardiol 2014;175:508514.

21 Jayachandran M, Chandrasekaran B, Namasivayam N: Geraniol attenuates oxidative stress by nrf2 activation in diet-induced experimental atherosclerosis. J Basic Clin Physiol Pharmacol 2015;26:335-346.

22 Hosoya T, Maruyama A, Kang MI, Kawatani Y, Shibata T, Uchida K, Warabi E, Noguchi N, Itoh K, Yamamoto M: Differential responses of the nrf2-keap1 system to laminar and oscillatory shear stresses in endothelial cells. J Biol Chem 2005;280:27244-27250.

23 Sussan TE, Jun J, Thimmulappa R, Bedja D, Antero M, Gabrielson KL, Polotsky VY, Biswal S: Disruption of nrf2, a key inducer of antioxidant defenses, attenuates apoe-mediated atherosclerosis in mice. PloS one 2008;3:e3791.

24 Ashino T, Yamamoto M, Yoshida T, Numazawa S: Redox-sensitive transcription factor nrf2 regulates vascular smooth muscle cell migration and neointimal hyperplasia. Arterioscler Thromb Vasc Biol 2013;33:760-768.

25 Levonen AL, Inkala M, Heikura T, Jauhiainen S, Jyrkkanen HK, Kansanen E, Maatta K, Romppanen E, Turunen P, Rutanen J, Yla-Herttuala S: Nrf2 gene transfer induces antioxidant enzymes and suppresses smooth muscle cell growth in vitro and reduces oxidative stress in rabbit aorta in vivo. Arterioscler Thromb Vasc Biol 2007;27:741-747.

26 Reddy SP: The antioxidant response element and oxidative stress modifiers in airway diseases. Curr Mol Med 2008;8:376-383.

27 Griendling KK, Sorescu D, Ushio-Fukai M: Nad(p)h oxidase: Role in cardiovascular biology and disease. Circ Res 2000;86:494-501.

28 Zhang G, Zhang F, Muh R, Yi F, Chalupsky K, Cai H, Li PL: Autocrine/paracrine pattern of superoxide production through nad(p)h oxidase in coronary arterial myocytes. Am J Physiol Heart Circ Physiol 2007;292:H483-495.

29 Ahmad M, Kelly MR, Zhao X, Kandhi S, Wolin MS: Roles for nox4 in the contractile response of bovine pulmonary arteries to hypoxia. Am J Physiol Heart Circ Physiol 2010;298:H1879-1888.

30 Bryan HK, Olayanju A, Goldring CE, Park BK: The nrf2 cell defence pathway: Keap1-dependent and -independent mechanisms of regulation. Biochem Pharmacol 2013;85:705-717.

31 Xue J, Wang S, Wu J, Hannafon BN, Ding WQ: Zinc at sub-cytotoxic concentrations induces heme oxygenase-1 expression in human cancer cells. Cell Physiol Biochem 2013;32:100-110.

32 Wang C, Li C, Peng H, Ye Z, Zhang J, Liu X, Lou T: Activation of the nrf2-are pathway attenuates hyperglycemia-mediated injuries in mouse podocytes. Cell Physiol Biochem 2014;34:891-902.

33 Wang S, Hannafon BN, Zhou J, Ding WQ: Clofibrate induces heme oxygenase 1 expression through a pparalpha-independent mechanism in human cancer cells. Cell Physiol Biochem 2013;32:1255-1264.

34 Zhang F, Jin S, Yi F, Xia M, Dewey WL, Li PL: Local production of o2- by nad(p)h oxidase in the sarcoplasmic reticulum of coronary arterial myocytes: Cadpr-mediated ca2+ regulation. Cell Signal 2008;20:637-644. 